\title{
A safe area for sternal puncture in children: an MSCT study based on sternal development
}

\author{
Xue Cui ${ }^{1} \cdot$ Rui-guang $\mathrm{Li}^{1} \cdot$ De-ting $\mathrm{Ma}^{1}$
}

Received: 21 May 2021 / Accepted: 11 October 2021 / Published online: 8 November 2021

(c) The Author(s), under exclusive licence to Springer-Verlag France SAS, part of Springer Nature 2021

\begin{abstract}
Purpose Multislice spiral CT (MSCT) was used to investigate the anatomical characteristics of sternal development, and to provide anatomical basis for sternal puncture in children.

Methods We retrospectively analyzed the thoracic MSCT data of 600 children who received thoracic MSCT from January to June 2020 with their age ranging from 1 month to 19 years. The distribution of sternal ossification centers and adjacent tissues and organs was observed. Subcutaneous soft tissue thickness and the distance between the skin and the posterior margin of the sternum were measured in the central areas of sternal manubrium and mesosternum (segments I and II), and the correlation between the two was calculated using linear correlation.

Results A total of 600 patients were enrolled, the mean age was 9.87 years and the standard deviation was 8.28 years. The sternal manubrium and ossification centers at the I and II segments of the mesosternum were visible in all cases (100\%). There was no ossification in segment III of the mesosternum in 15 cases (2.5\%), including 12 cases (80\%) adjacent to the posterior pericardium and 7 cases (46.7\%) of lung tissue. There were 274 cases (45.7\%) of segment IV without ossification, including 204 cases $(74.5 \%)$ of adjacent pericardium and 95 cases $(32.8 \%)$ of lung tissue. The xiphoid process was not ossified in 258 cases (43\%), including 190 cases (73.6\%) adjacent to the pericardium and 97 cases $(37.6 \%)$ adjacent to the lung tissue. Correspondingly, the thickness of subcutaneous soft tissue of the sternal manubrium and the central region of the I and II segments of the mesosternum had a low positive correlation with age $(P<0.001)$, the distance between the skin and the posterior margin of the sternum showed a moderate positive correlation with age $(P<0.001)$, and the distance between the skin and the posterior margin of the sternum showed a high positive correlation with the thickness of subcutaneous soft tissue $(P<0.001)$.

Conclusions Nonossification of the sternal ossification center usually occurs below segment III of the mesosternum and is usually adjacent to heart and lung tissue. Pediatric sternal puncture should be performed at the sternal manubrium and the mesosternum of segments I and II. However, attention should be paid to the space between multiple ossification centers. The thickness of subcutaneous soft tissue is a critical factor that determines the depth of the puncture.
\end{abstract}

Keywords Children $\cdot$ Sternum $\cdot$ Ossification centers $\cdot$ Sternal puncture $\cdot$ Computer tomography

\section{Introduction}

The sternum, which consists of sternal manubrium, mesosternum (body) and xiphoid process, is an important site for bone marrow aspiration, bone marrow biopsy, acupuncture,

De-ting Ma

medimage@163.com

1 Department of Radiology, Tai' an City Central Hospital, Shandong First Medical University and Shandong Academy of Medical Sciences, Tai' an, Shandong Province 271000, People's Republic of China and an important approach for chest surgery [1-6]. However, there are many developmental changes in the sternum in children, such as the ossification centers have not been ossified, and there are still gaps between ossification centers because they have not been fused. If these developmental changes are ignored, there are potential risks of cardiac tamponade, pneumothorax and mediastinal emphysema caused by needle puncture into the sternal tissue [7-9]. Therefore, it is necessary to correctly understand the development and ossification characteristics of the sternum in children, and to know the thickness of the sternum and subcutaneous soft tissue as well as the posterior adjacent tissues of the sternum. 
MSCT has the advantages of high resolution, fast scanning speed, intuitive and clear imaging. Maximum intensity projections (MIP) and volume rendering technology (VRT) were used to capture the ossification and shape of the sternum and costal cartilage from multiple angles and directions [10]. The purpose of this study was use MSCT to observe the distribution of sternal ossification center and adjacent tissues behind the sternum, and measure the thickness of the sternum and subcutaneous soft tissue, so as to guide the clinical exploration of the safe area of sternal puncture in children.

\section{Methods}

\section{Patients}

The imaging data of patients who underwent thoracic MSCT examination were retrospectively analyzed in our hospital from January to June 2020. Inclusion criteria: (1) all patients were under 20 years old; (2) volume scanning, which can be post-processed, and (3) the post-processing image is good without artifact. Exclusion criteria: (1) underlying disease causing developmental delay; (2) thoracic deformities due to trauma, surgery, or congenital development, and (3) underlying condition leading to osteoclasts.

A total of 600 patients were enrolled, including 300 males and 300 females. They underwent necessary thoracic MSCT examination, with indications of pulmonary infection (263 cases), foreign body inhalation (50 cases), and COVID-19 screening (287 cases) for hospitalization in the department of pediatric, oral, eye, and otolaryngology.

The hospital ethics committee approved the study because it was a retrospective study and agreed to exempt patients from the informed consent requirement.

\section{Inspection equipment and imaging}

A 256-multislice CT scanner (Brilliance iCT, Philips, the Netherlands) was used for all the thoracic CT procedures. Scanning parameters: tube voltage was $100 \mathrm{kV}$, tube current was in automatic mode, collimator width was $8 \mathrm{~cm}$, scanning pitch was 0.992 , rotation time was $0.5 \mathrm{~s}$, scanning layer thickness was $5.0 \mathrm{~mm}$, layer spacing was $5.0 \mathrm{~mm}$, reconstruction layer thickness was $1 \mathrm{~mm}$, layer spacing was $0.9 \mathrm{~mm}$, matrix: $512 \times 512$. Multi-planner reformation (MPR) was performed on the workstation, and MIP and VRT images were performed on the sternum in coronal view.

\section{Image analysis}

The evaluation was conducted by two diagnostic physicians who had been working on CT diagnosis for more than
10 years, when the results are inconsistent, discussions were made to reach agreement. To visualize the sternal structure, transverse, sagittal, and coronal MPR images, coronal MIP and VRT images were evaluated. The number of sternal segments was calculated by costochondral junction (CCJ). For example, between the first and second $\mathrm{CCJ}$ is the sternal manubrium, between the second and third CCJ is the segment I of mesosternum, between the third and fourth CCJ is the segment II of mesosternum, between the fourth and fifth CCJ is the segment III of mesosternum, and between the fifth and sixth CCJ is the segment IV of mesosternum.

The image evaluation included: (1) the number of segments and the number of ossification centers in manubrium, mesosternum and xiphoid process; (2) the vertical fusion between segments and horizontal fusion between ossification centers in the same segment; (3) the neighboring intrathoracic organs (such as mediastinal fat, lung and pericardium) to the unossified areas of the sternum.

\section{Image measurement}

Data measurement was conducted independently by two physicians in a double-blind method, and the measurement data were the average of the measurement results of the two physicians. If the difference between the measurements of two physicians was high, they resolved differences via discussion. In combination with the median sternal sagittal MPR, transverse MPR, the subcutaneous soft tissue thickness (Fig. 1), the distance between the skin and the posterior margin of the sternum (Fig. 1), and the distance between the skin and the anterior margin of the sternum (Fig. 1) were measured at the manubrium sternum, the central area of the mesosternum at segments I and II.

\section{Statistical analysis}

SPSS 26.0 statistical software package was used for descriptive statistical analysis of the data. Measurement data were expressed as mean \pm standard deviation $(\bar{x} \pm s)$. One-way ANOVA was used for comparison among age groups and indicators. Linear correlation was used to analyze the correlation between each measurement index and age. Correlation strength: $r \geq 0.7$ was highly correlated, $0.4 \leq r<0.7$ was moderately correlated, $0.2 \leq r<0.4$ was weakly correlated, and $r<0.2$ was weakly correlated. The reliability of the two performers' measurements was evaluated by intraclass correlation coefficient (ICC). An ICC value less than 0.50 indicates poor reliability, between 0.50 and 0.75 indicates moderate reliability, between 0.75 and 0.90 indicates good reliability, and a value greater than 0.90 indicates excellent reliability. $P<0.05$ indicated that the difference was statistically significant. 


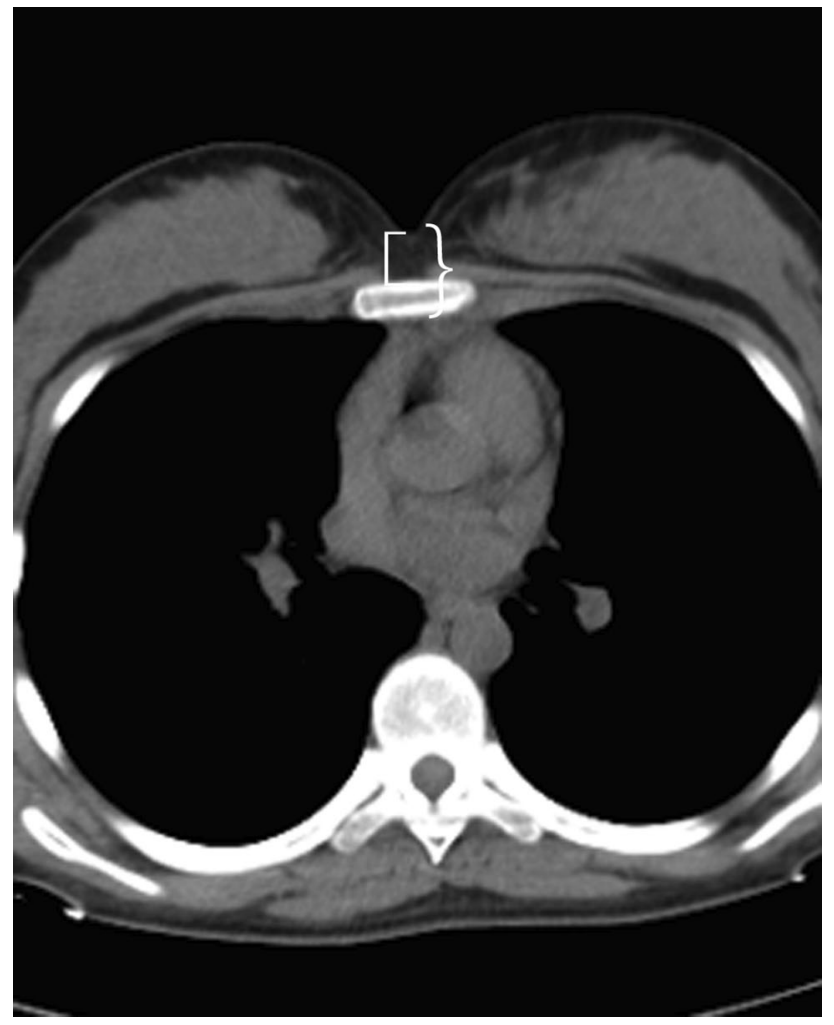

Fig. 1 Measurement of subcutaneous soft tissue thickness (square bracket), the distance from skin to the posterior edge of the sternum (curly bracket), and sternum thickness

\section{Results}

A total of 600 patients were enrolled, including 300 males and 300 females, ranging in age from 1 month to 19 years and 11 months, with a mean age of 9.87 years and a standard deviation of 8.28 years.

\section{Distribution of sternal ossification centers (Tables 1 and 2) and adjacent tissues (Tables 3)}

The sternal manubrium had a single midline ossification center in 558 patients (93\%), and two or more ossification centers in 42 patients (7\%, Fig. 2A). There were 32 cases (76.2\%, Fig. $2 \mathrm{~B}$ ) adjacent to the posterior thymus and 10 cases $(23.8 \%)$ adjacent to the lung tissue of multiple ossification centers.

Segment IV has more non-ossification cases (274 cases, $45.7 \%$, Fig. 3A) than any other sections, including 186 cases (67.9\%, Fig. 3B) of posterior adjacent pericardium, 86 cases (31.4\%) of lung tissue, and 2 cases $(0.7 \%)$ of mediastinal fat. The second is the segment III (15 cases, $2.5 \%$ ), including the posterior adjacent pericardium ( 6 cases, $40.0 \%$ ), lung tissue (7 cases, $46.7 \%$, Fig. 3C), and thymus ( 2 cases, $13.3 \%$ ).

The mesosternum consisted of 2 segments in 15 cases (2.5\%), 3 segments in 274 cases (45.7\%), and 4 segments in 311 cases (51.8\%, Fig. 4).
Table 1 Distribution of sternal ossification centers, sex and age

\begin{tabular}{|c|c|c|c|c|c|c|c|c|c|c|c|c|c|}
\hline \multirow[t]{2}{*}{ Age } & \multicolumn{4}{|c|}{$\begin{array}{l}\text { Number of sternal manu- } \\
\text { brium ossification center }\end{array}$} & \multicolumn{3}{|c|}{ Fusing sternum } & \multicolumn{3}{|c|}{$\begin{array}{l}\text { Number of sternal } \\
\text { segments }\end{array}$} & \multicolumn{3}{|c|}{$\begin{array}{l}\text { Number of ossifi- } \\
\text { cation centers in } \\
\text { xiphoid process }\end{array}$} \\
\hline & One & Two & Three & Four & All & Part & None & Two & Three & Four & None & One & Two \\
\hline$y<5$ & 116 & 26 & 8 & 0 & 0 & 12 & 138 & 6 & 93 & 51 & 76 & 74 & 0 \\
\hline $5 \leq y<10$ & 143 & 4 & 3 & 0 & 1 & 40 & 109 & 6 & 82 & 62 & 81 & 69 & 0 \\
\hline $10 \leq y<15$ & 150 & 0 & 0 & 0 & 8 & 103 & 39 & 1 & 48 & 101 & 78 & 72 & 0 \\
\hline $15 \leq y<20$ & 149 & 1 & 0 & 0 & 84 & 50 & 16 & 2 & 51 & 97 & 23 & 122 & 5 \\
\hline Total & 558 & 31 & 11 & 0 & 93 & 205 & 302 & 15 & 274 & 311 & 258 & 337 & 5 \\
\hline
\end{tabular}

\begin{tabular}{|c|c|c|c|c|c|c|c|c|c|}
\hline \multirow{2}{*}{$\begin{array}{l}\text { Age } \\
\text { Sternal segment }\end{array}$} & \multicolumn{2}{|c|}{$\begin{array}{l}\text { Two sternal } \\
\text { segments }\end{array}$} & \multicolumn{3}{|c|}{ Three sternal segments } & \multicolumn{4}{|c|}{ Four sternal segments } \\
\hline & I & II & I & II & III & I & II & III & IV \\
\hline$y<5$ & 0 & 0 & 0 & $6(2)$ & $21(12)$ & 0 & $3(1)$ & $10(8)$ & $7(4)$ \\
\hline $5 \leq y<10$ & 0 & 1 & 1 & $1(1)$ & $12(7)$ & 0 & 0 & $7(2)$ & $13(9)$ \\
\hline $10 \leq y<15$ & 0 & 0 & 0 & $2(1)$ & $5(3)$ & 0 & 0 & $7(2)$ & $12(3)$ \\
\hline $15 \leq y<20$ & 0 & 0 & 0 & 0 & 1 & 0 & 0 & 1 & $3(2)$ \\
\hline Total & 0 & 1 & $1(1)$ & $9(4)$ & $39(22)$ & 0 & $3(1)$ & $25(12)$ & $35(18)$ \\
\hline
\end{tabular}

The data in () represent the number of cases where two or more ossification centers did not fuse with each other 
Table 3 Adjacent tissues in the unossified/unfused sternal region

\begin{tabular}{|c|c|c|c|c|c|c|c|}
\hline Region & Number & Adjacent tissues & $\mathrm{y}<5$ & $5 \leq y<10$ & $10 \leq y<15$ & $15 \leq y<20$ & Total \\
\hline \multirow[t]{4}{*}{ The manubrium sternum has $2-4$ ossification centers } & \multirow[t]{4}{*}{42} & Thymus & 28 & 4 & 0 & 0 & 32 \\
\hline & & Lung & 8 & 2 & 0 & 0 & 10 \\
\hline & & Blood vessels & 0 & 0 & 0 & 0 & 0 \\
\hline & & Fat & 0 & 0 & 0 & 0 & 0 \\
\hline \multirow[t]{5}{*}{ Sternal manubrium—body is not fusion } & \multirow[t]{5}{*}{579} & Thymus & 114 & 116 & 47 & 3 & 280 \\
\hline & & Lung & 35 & 29 & 86 & 114 & 264 \\
\hline & & Blood vessels & 0 & 0 & 0 & 0 & 0 \\
\hline & & Fat & 1 & 3 & 8 & 15 & 27 \\
\hline & & Pericardium & 0 & 0 & 3 & 5 & 8 \\
\hline \multirow[t]{5}{*}{ The mesosternum segment I-II is not fusion } & \multirow[t]{5}{*}{362} & Thymus & 86 & 58 & 10 & 0 & 154 \\
\hline & & Lung & 57 & 51 & 55 & 11 & 174 \\
\hline & & Blood vessels & 0 & 0 & 0 & 0 & 0 \\
\hline & & Fat & 0 & 2 & 4 & 0 & 6 \\
\hline & & Pericardium & 4 & 9 & 13 & 2 & 28 \\
\hline \multirow[t]{4}{*}{ The mesosternum segment III is not ossified } & \multirow[t]{4}{*}{15} & Lung & 2 & 2 & 1 & 2 & 7 \\
\hline & & Thymus & 2 & 0 & 0 & 0 & 2 \\
\hline & & Fat & 0 & 0 & 0 & 0 & 0 \\
\hline & & Pericardium & 3 & 2 & 0 & 1 & 6 \\
\hline \multirow[t]{3}{*}{ The mesosternum segment IV is not ossified } & \multirow[t]{3}{*}{274} & Lung & 33 & 27 & 18 & 8 & 86 \\
\hline & & Fat & 1 & 0 & 1 & 0 & 2 \\
\hline & & Pericardium & 66 & 63 & 34 & 23 & 186 \\
\hline \multirow[t]{4}{*}{ The xiphoid process is not ossified } & \multirow[t]{4}{*}{258} & Lung & 30 & 23 & 30 & 3 & 86 \\
\hline & & Fat & 0 & 0 & 0 & 0 & 0 \\
\hline & & Liver/diaphragm & 1 & 0 & 3 & 0 & 4 \\
\hline & & Pericardium & 45 & 61 & 47 & 15 & 168 \\
\hline \multirow[t]{3}{*}{ Segment I contains two ossification centers } & \multirow[t]{3}{*}{1} & Thymus & 0 & 1 & 0 & 0 & 1 \\
\hline & & Lung & 0 & 0 & 0 & 0 & 0 \\
\hline & & Pericardium & 0 & 0 & 0 & 0 & 0 \\
\hline \multirow[t]{3}{*}{ Segment II contains two ossification centers } & \multirow[t]{3}{*}{5} & Thymus & 2 & 0 & 0 & 0 & 2 \\
\hline & & Lung & 0 & 0 & 0 & 0 & 0 \\
\hline & & Pericardium & 1 & 1 & 1 & 0 & 3 \\
\hline \multirow[t]{3}{*}{ Segment III contains two ossification centers } & \multirow[t]{3}{*}{34} & Thymus & 1 & 0 & 0 & 0 & 1 \\
\hline & & Lung & 9 & 1 & 1 & 0 & 11 \\
\hline & & Pericardium & 10 & 8 & 4 & 0 & 22 \\
\hline \multirow[t]{3}{*}{ Segment IV contains two ossification centers } & \multirow[t]{3}{*}{18} & Thymus & 1 & 0 & 0 & 0 & 1 \\
\hline & & Lung & 1 & 5 & 2 & 0 & 8 \\
\hline & & Pericardium & 2 & 4 & 1 & 2 & 9 \\
\hline
\end{tabular}

A total of 113 segments of the mesosternum contained 2 ossification centers, including 35 patients $(31.0 \%)$ in segment IV, 64 patients (56.6\%, Fig. 5) in segment III, 13 patients $(11.5 \%)$ in segment II, and 1 patient $(0.8 \%)$ in segment I.

258 cases $(43.0 \%$, Fig. 6A) did not show ossification center in the xiphoid process, including 168 cases $(65.1 \%$, Fig. 6B) adjacent to the pericardium, 86 cases (33.3\%) of lung tissue, and 4 cases (1.6\%) of liver/ diaphragm.

\section{Fusion of sternal ossification centers (Tables 1 and 2) and adjacent tissues (Table 3 )}

The manubrium and mesosternum were fused in 21 cases (3.5\%), the youngest was 8 years old. There were 579 cases $(96.5 \%)$ without fusion, and the oldest was 19 years and 11 months old. They were adjacent to lung tissue in 264 cases $(45.6 \%)$, thymus in 280 cases $(48.3 \%$, Fig. 2 C), pericardium in 8 cases $(1.4 \%)$, and mediastinal fat in 27 cases $(4.7 \%)$. The segment of mesosternum contained 
Fig. 2 MIP (A) and crosssectional MPR (B, C) images of the sternum of a woman aged 1 year and 5 months. A The multiple ossification centers of the sternal manubrium are not fully fused (arrow). B The posterior adjacent tissue of the sternal manubrium is the thymus (*). $\mathbf{C}$ The posterior adjacent tissue of the stalk joint is the thymus gland $(*)$
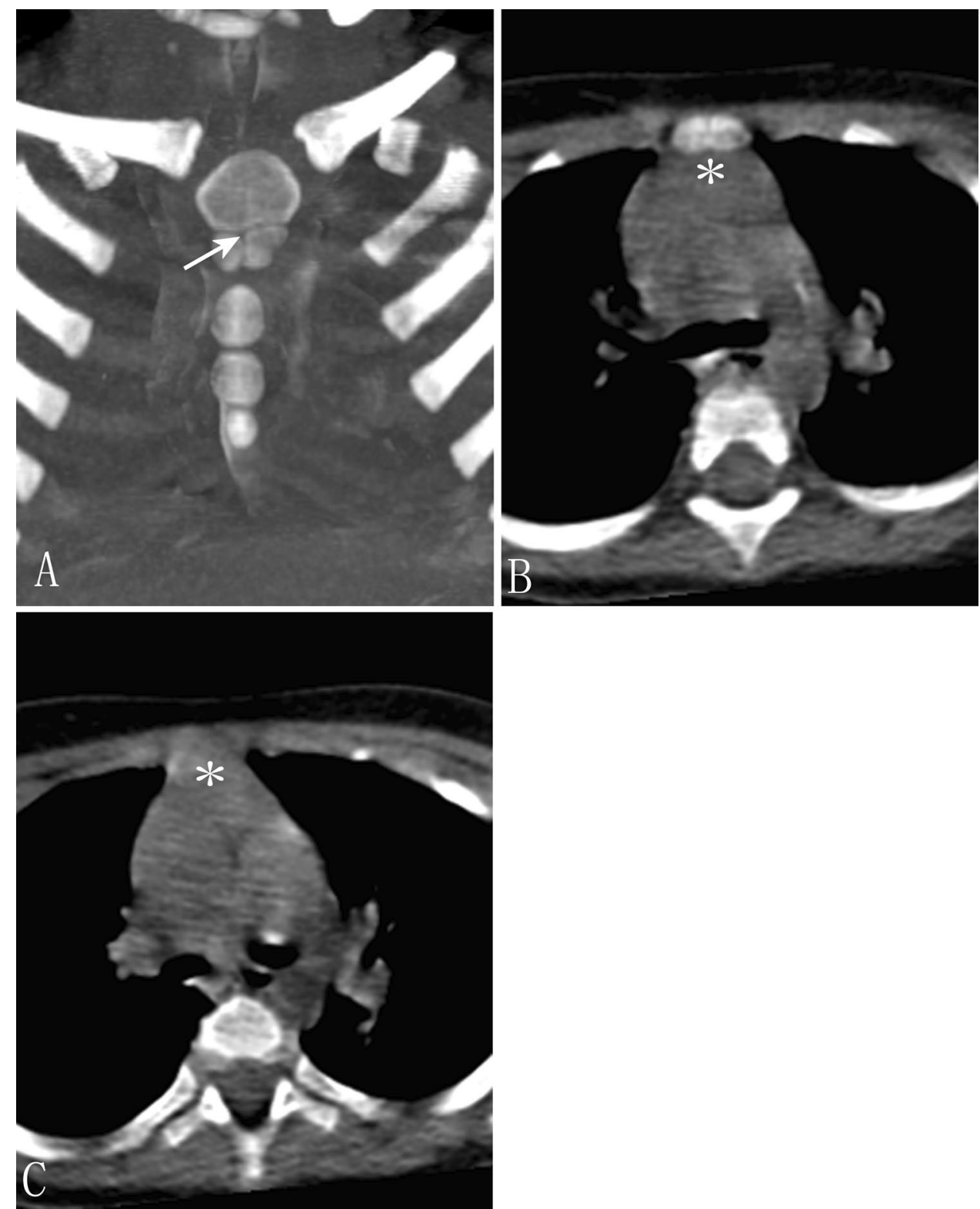

two ossification centers, in which 58 cases (51.3\%) were unfused and 55 cases $(48.7 \%)$ were partially fused. The specific distribution was as follows: 1 case $(2.9 \%)$ adjacent to the thymus, 14 cases (40.0\%) lung tissue, 20 cases $(57.1 \%)$ pericardium in segment IV; segment III adjacent to thymus in 3 cases (4.7\%), lung tissue in 27 cases $(42.2 \%)$, pericardium in 34 cases $(53.1 \%)$; segment II adjacent to thymus in 4 cases $(30.7 \%)$, lung tissue in 4 cases $(30.7 \%)$, pericardium in 5 cases $(38.5 \%)$; segment I adjoining thymus in 1 case $(100 \%)$.

There were 362 cases of unfusion between the I and II segments of the mesostrnum (Fig. 3A), with their age ranging from 1 month to 18 years and 2 months, including 174 cases $(48.1 \%)$ of posterior adjacent lung tissue, 154 cases
(42.5\%) of thymus, 28 cases (7.7\%) of pericardium, and 5 cases $(1.4 \%)$ of mediastinal fat.

The mesostrenum was fused completely (Fig. 6A) in 93 cases $(15.5 \%)$, with the earliest age of 6 years and 7 months. There were 302 cases (50.3\%) with the oldest age of 19 years and 5 months without sternal fusion.

\section{Correlation between measurement indexes of sternum and location and age (Table 4)}

The ICC values measured by the two physicians are $0.92 \sim 0.97$, indicating high reliability.

The thickness of subcutaneous soft tissue in the central area of the manubrium was slightly positively correlated with age $(r=0.240, P=0.000)$, the distance between skin 
Fig. 3 MIP (A) and crosssectional MPR $(\mathbf{B}, \mathbf{C})$ images of the sternum of a 4-year-old male. A The III and IV segments of the mesosternum are not ossified (square brackets), and the I and II segments are not fused (arrows). B Segment IV adjacent tissue of the unossified area is the pericardium (arrow). C Segment III adjacent tissue of the unossified area is the right lung (arrow)
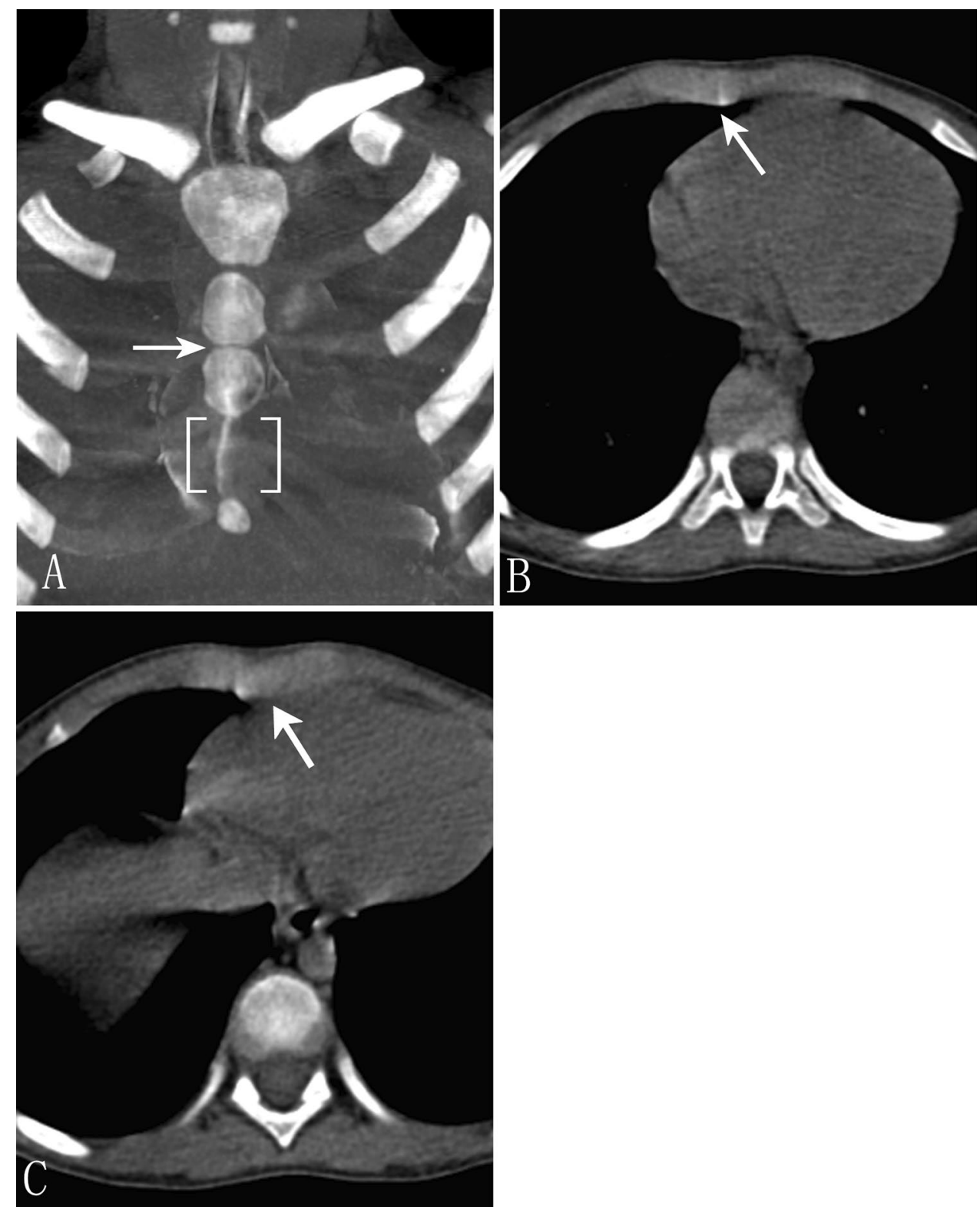

and the posterior margin of the sternum was moderately positively correlated with age $(r=0.449, P=0.000)$, and the thickness of the sternum was moderately positively correlated with age $(r=0.664, P=0.000)$. The distance between skin and the posterior margin of the sternum was highly positively correlated with subcutaneous soft tissue thickness $(r=0.932, P=0.000)$ and moderately positively correlated with sternal thickness $(r=0.630, P=0.000)$.

The thickness of subcutaneous soft tissue in the central area of segment I of the mesosternum showed a low positive correlation with age $(r=0.292, P=0.000)$, while the distance between skin and posterior margin of the sternum showed a moderate positive correlation with age $(r=0.459$, $P=0.000)$. There was a moderate positive correlation between sternal thickness and age $(\mathrm{r}=0.650, \mathrm{P}=0.000)$.
The distance between skin and the posterior margin of the sternum was highly positively correlated with subcutaneous soft tissue thickness $(r=0.951, P=0.000)$ and moderately positively correlated with sternal thickness $(r=0.594$, $P=0.000$ ).

The thickness of subcutaneous soft tissue in the central region of the II segment of the mesosternum was slightly positively correlated with age $(r=0.341, P=0.000)$, and the distance between skin and the posterior margin of the sternum was moderately positively correlated with age ( $r=0.490, P=0.000)$. Sternal thickness was highly positively correlated with age $(r=0.701, P=0.000)$. The distance between skin and the posterior margin of the sternum was highly positively correlated with subcutaneous soft tissue thickness $(r=0.966, P=0.000)$ and moderately 
Fig. 4 MIP (A) and cross-sectional MPR (B) images of the sternum of a man aged 1 year and 6 months. A No fusion of the III and IV segments (arrow). B The posterior adjoining tissue is the pericardium (arrow)
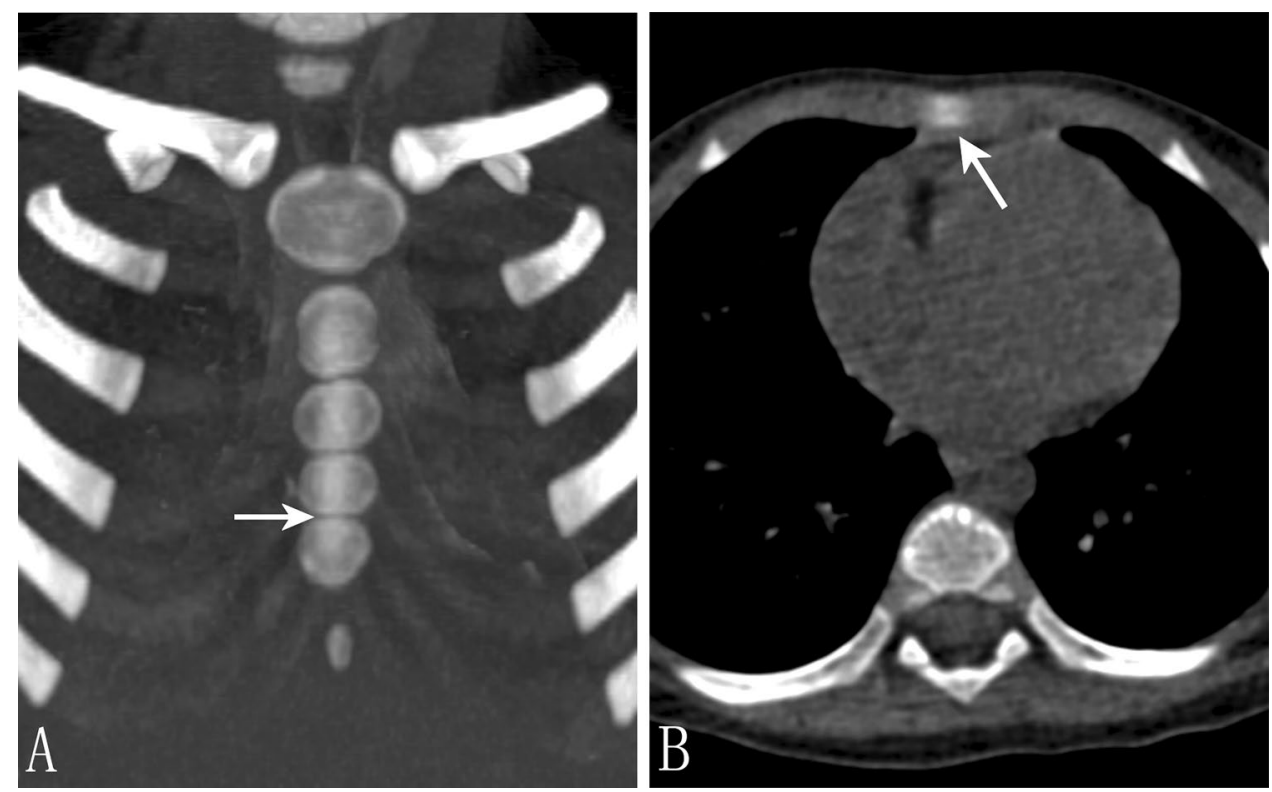

positively correlated with sternal thickness $(r=0.592$, $P=0.000)$.

\section{Discussions}

Embryologically, the sternum develops from two parallel mesenchymal strips, which begin to fuse head and tail at 9 weeks of fetal life $[1,3,4,6]$. When fusion occurs, ossification centers appear in the same cephalic direction. If the sternal segment begins to ossify before the mesenchymal strips fuse, there will be two separate ossification centers in the sternal segment [6]. There are multiple ossification centers in the sternum, and the relationship between ossification and fusion in ossification centers and age, subcutaneous soft tissue thickness and sternal thickness are all factors to evaluate the safety range of sternal biopsy or puncture in children [9].

\section{Characteristics of sternum development and adjacent tissues in children}

The sternal manubrium has at least one ossification center, and multiple ossification centers are usually fused before birth [6]. In this study, $7 \%$ of the patients had multiple ossification centers on the sternal manubrium, $76.2 \%$ had adjacent thymus, in adults, neighboring structures are usually major vessels [9]. Literature has reported a case of pulsating bleeding caused by adult sternal manubrium puncture through ascending aorta [9]. As an important site for clinical bone marrow biopsy [8], the accurate preoperative assessment of the status of the sternal manubrium is conducive to avoiding surgical complications.
The mesosternum has a varying number of ossified segments, usually developed from four separate segments [1, $3,4,6]$. All patients in this study had at least two segments. Fusion between ossifying centers can be classified as nonfusion (ossifying centers are separated from each other), complete fusion (no trace of fusion between ossifying centers can be seen, and it can only be judged by the connection of costal cartilage), and partial fusion. It is mentioned in the literature that the fused features and the length of the mesosternum can be used to predict the height. Due to the distinct individual difference in sternum shape, it can be compared with the image of the deceased to confirm their gender $[11,12]$. Complete fusion of each segment of the sternum is usually completed at the age of 25 years [7, 13]. In this study, complete fusion of the mesosternum mostly occurred in the 15-20 age group, and ossification of segment IV and xiphoid process varied greatly among individuals $[7,13]$. In this study, unossification of segment IV was the most common, with an incidence of $45.7 \%$, its most common adjacent tissue was pericardium (67.9\%), followed by lung tissue (31.4\%). The presence of section III unossified tissue was in $2.5 \%$ of children, its common adjacent tissues were lung tissue (46.7\%) and pericardium (40.0\%). The presence of two ossification centers is most common in segment III and usually occurs in children under 5 years old.

The xiphoid process is the most variable ossification center of the sternum $[1,6]$. In this study, about half of the children had a single ossification center, and a few had two ossification centers. In the other half of the children, the xiphoid process was indeed absent, while in adults, the xiphoid process was rarely absent, indicating that the absence of the xiphoid process in children or adolescents should be considered as not yet ossified. In this study, the 
Fig. 5 MIP (A) and crosssectional MPR $(\mathbf{B}, \mathbf{C})$ images of the sternum of a man aged 1 year and 5 months. A Double ossification centers in the II and III segments, not fused between them (arrows). B The posterior adjacent structure of the ossification center is the pericardium (arrow). C The posterior adjacent tissue of the ossification center is the pericardium $(*)$, and the gap between the ossification centers is visible (arrow)
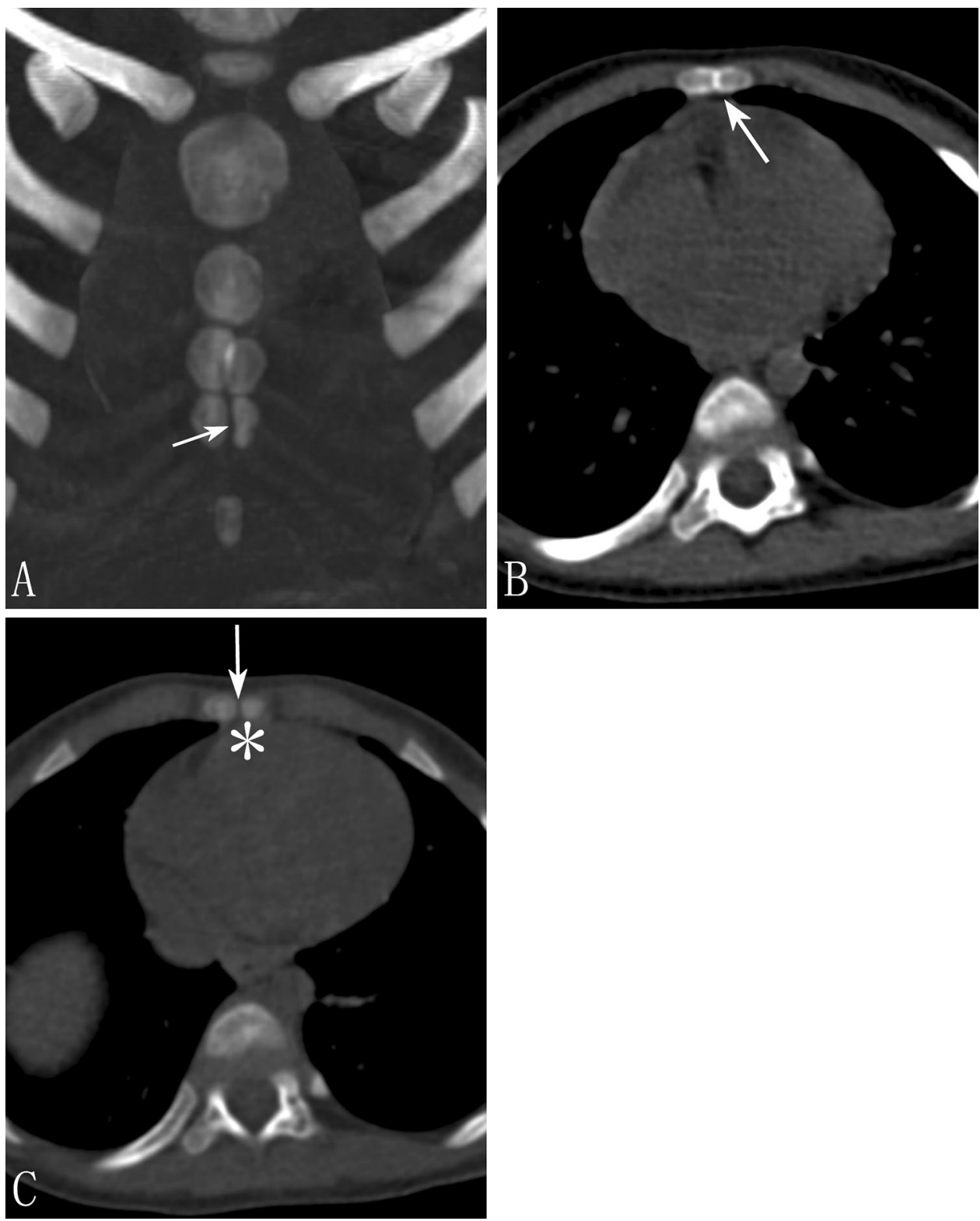

unossified xiphoid process adjacent to the pericardium accounted for $65.1 \%$, lung tissue $33.3 \%$, and liver/diaphragm $1.6 \%$.

These findings suggest that the presence of unossified sternal ossification centers in segments III and IV and xiphoid processes during childhood, as well as adjacent pericardium and lung tissue, may be one of the main reasons for not using this area clinically as a puncture site.

\section{Site of sternal puncture in children}

This study showed that all children had ossification centers at the manubrinm and the I and II segments of the mesosternum, while the III and IV segments of the mesosternum and the xiphoid process were mostly unossified and adjacent to the lung tissue or pericardium. The sternal variations, such as sternal foramen and fissure, were most frequently common in segment III and IV and xiphoid process [13-15]. Therefore, pediatric sternal puncture should avoid the substernal segment, and the sternal manubrium, the I and II segments of the mesosternum should be selected. However, there are also many changes in the development of the manubrium sternum and the I and II segments of the mesosternum. For example, there is a gap between the multiple ossification centers of the sternal manubrium without fusion, and the fusion time between the I and II ossification centers of the mesosternum is late [1]. The fusion between the manubrium sternum and the mesosternum and the fusion between the mesosternum and the xiphoid process had great variability. Some had 
Fig. 6 MIP (A) and cross-sectional MPR (B) images of the sternum of a man aged 15 year and 6 months. A The xiphoid process is unossified (square brackets), and the mesosternum is completely fused (curly bracket). B The adjacent tissue of the unossified xiphoid process is the pericardium (arrow)
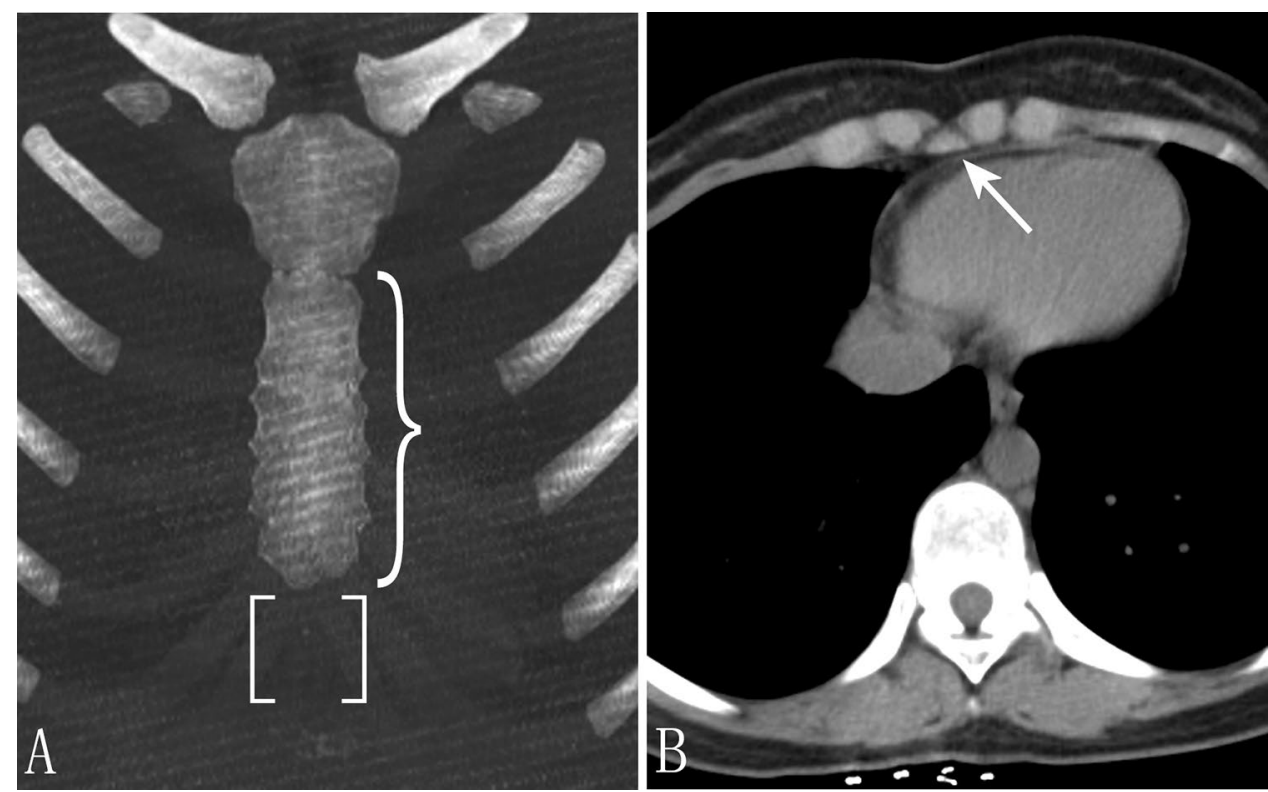

Table 4 Distribution of sternum measurements and age

\begin{tabular}{lclc}
\hline Age Groups & Subcutaneous soft tissue thickness & $\begin{array}{l}\text { Distance from skin to posterior margin } \\
\text { of the sternum }\end{array}$ & $\begin{array}{l}\text { The thickness of the sternum } \\
\text { Central area of the manubriumsternum }\end{array}$ \\
$\mathrm{y}<5$ & $7.81 \pm 2.68(1.98-20.10)$ & $15.59 \pm 2.62(10.76-27.34)$ & $7.78 \pm 1.58(4.47-13.63)$ \\
$5 \leq \mathrm{y}<10$ & $8.02 \pm 5.07(2.08-26.08)$ & $18.75 \pm 6.09(10.62-40.4)$ & $10.72 \pm 1.73(7.42-16.14)$ \\
$10 \leq \mathrm{y}<15$ & $11.51 \pm 8.04(2.06-40.62)$ & $23.06 \pm 8.80(11.94-56.94)$ & $11.55 \pm 2.68(4.84-20.86)$ \\
$15 \leq \mathrm{y}<20$ & $11.60 \pm 8.01(3.17-56.66)$ & $25.04 \pm 9.35(13.35-70.57)$ & $13.44 \pm 3.00(7.84-24.38)$ \\
Total & $9.73 \pm 6.59(1.98-56.66)$ & $20.64 \pm 8.21(10.62-70.57)$ & $10.91 \pm 3.09(4.47-24.38)$ \\
Central segment I of the mesosternum & & $7.03 \pm 1.10(3.80-9.74)$ \\
$\mathrm{y}<5$ & $5.87 \pm 2.44(1.92-16.19)$ & $12.91 \pm 2.35(8.57-21.94)$ & $9.01 \pm 1.54(3.49-17.56)$ \\
$5 \leq \mathrm{y}<10$ & $6.32 \pm 4.14(1.77-21.24)$ & $15.22 \pm 4.88(9.23-33.27)$ & $10.00 \pm 1.68(5.75-14.78)$ \\
$10 \leq \mathrm{y}<15$ & $9.75 \pm 6.81(1.66-39.44)$ & $19.76 \pm 7.53(10.47-53.28)$ & $10.86 \pm 2.38(6.27-26.45)$ \\
$15 \leq \mathrm{y}<20$ & $9.96 \pm 7.29(2.26-53.11)$ & $20.82 \pm 7.93(11.48-66.01)$ & $9.23 \pm 2.25(3.8-26.45)$ \\
Total & $7.98 \pm 5.85(1.66-53.11)$ & $17.20 \pm 6.90(8.57-66.01)$ & \\
Central segment II of the mesosternum & & $11.51 \pm 2.11(7.58-20.58)$ & $6.34 \pm 0.94(3.83-8.92)$ \\
$\mathrm{y}<5$ & $5.18 \pm 2.23(1.3-13.58)$ & $13.60 \pm 4.28(7.04-30.04)$ & $7.90 \pm 1.08(5.01-10.65)$ \\
$5 \leq \mathrm{y}<10$ & $5.70 \pm 3.74(1.2-20.74)$ & $18.40 \pm 7.42(8.48-51.97)$ & $9.13 \pm 1.61(6.33-16.83)$ \\
$10 \leq \mathrm{y}<15$ & $9.27 \pm 6.71(1.14-41.14)$ & $19.47 \pm 7.32(10.68-53.09)$ & $9.61 \pm 1.54(5.87-13.95)$ \\
$15 \leq \mathrm{y}<20$ & $9.86 \pm 7.65(1.93-45.06)$ & $15.75 \pm 6.61(7.04-53.09)$ & $8.24 \pm 1.83(3.83-16.83)$ \\
Total & $7.50 \pm 5.72(1.14-45.06)$ & & \\
\hline
\end{tabular}

completely fused in the early age, while others fused much later [6]. Therefore, when performing acupuncture or bone marrow biopsy on young children, it should be avoided to insert the needle into the unfused space of the ossification center, resulting in posterior sternal tissue injury. In short, in addition to selecting the site of bone marrow puncture in the sternal manubrium or the central area of the I and II mesosternal segments, attention should also be paid to the fusion status of multiple ossification centers.

\section{Depth of sternal puncture or biopsy in children}

The length of the puncture or biopsy needle determines the depth of the puncture or biopsy. If it is too shallow, it cannot penetrate the sternum; if it is too deep, it may penetrate the sternum and enter the posterior sternum tissue, causing damage to the internal organs in the chest [7-9]. One case of acute A-type aortic dissection after sternal puncture was reported in the literature [7], and one case of sternal 
puncture with a $90 \mathrm{~mm}$ puncture needle through the second and third intercostals was reported in the literature, and aneurysm ruptured due to the penetration of the weak sternal puncture needle through the sternum, resulting in the death of the patient [9]. Bone marrow aspiration needles are available in different types and sizes with replaceable safety plugs. However, a plug does not necessarily prevent deeper tissue from penetrating [8]. The pressure on the sternum during needle propulsion may cause deformation of the thoracic cavity, leading to the needle reaching the anterior wall of the ascending aorta [8]. Therefore, it is of great significance to accurately understand the thickness of subcutaneous soft tissue and sternum for adjusting the length of needle during sternum puncture and acupuncture.

In this study, the distance between skin and posterior sternal margin, subcutaneous soft tissue thickness, and sternal thickness were measured in the sternal manubrium, the central area of the mesosternumat segments I and II. The results showed that the distance from skin to posterior sternal margin was highly positively correlated with subcutaneous soft tissue thickness, and moderately positively correlated with age and sternal thickness. Therefore, the penetration depth of puncture needle is closely related to subcutaneous soft tissue thickness, which also changes in childhood. In this study, subcutaneous soft tissue thickness has a low degree of positive correlation with age, and body mass index is significantly positively correlated with the distance between the skin and the posterior margin of the sternum as mentioned in the literature [8]. In this study, the maximum thickness of subcutaneous soft tissue and the distance from skin to posterior sternal margin measured were $56.66 \mathrm{~mm}$ and $70.57 \mathrm{~mm}$, respectively, which were close to or more than the maximum length commonly used for bone marrow aspiration needle. Therefore, preoperative evaluation of subcutaneous soft tissue thickness and the distance from skin to posterior sternal margin in obese children was very necessary.

Subcutaneous soft tissue thickness, the distance from the skin to the posterior margin of the sternum, and the thickness of the sternum vary in different parts of the sternum. The literature indicates that at the 2 nd intercostal level, the sternum thickness in adults was $13.0 \pm 0.2 \mathrm{~mm}$ [8], whereas in this study, the sternum thickness in children was $9.23 \pm 2.25 \mathrm{~mm}$ and was moderately positively correlated with age. Therefore, the depth of the puncture should be between the thickness of the subcutaneous soft tissue and the distance from the skin to the posterior margin of the sternum, and the effect of the puncture site on the length of the puncture needle should also be paid attention to.

Our study helps clinicians to better understand the development of the sternum and its adjacent tissues, which provides a reference for invasive sternum surgery to avoid complications. In our hospital, chest CT examination is the primary preoperative evaluation before invasive sternal or chest surgery in all children, and the use of automated lowdose scans minimizes radiation exposure in children.

\section{Conclusion}

The unossified sternal segment in children is more common in xiphoid process, and the III and IV segments of the mesosternum, adjacent to the pericardium and lung tissue, and there are risks of serious complications such as pneumothorax or cardiac tampering during sternal acupuncture. To avoid complications, sternal manubrium and the central area of the I and II segments should be selected, and the gap between the unfused ossification centers should be noted. The depth of puncture should take into account the different thickness and location of subcutaneous soft tissue. However, due to the large individual differences, to minimize the risk of fatal complications, familiarity with the developmental characteristics of the sternum is beneficial to the safety of sternum puncture or biopsy.

Author contributions CX: Data collection, data analysis, manuscript writing and editing. LRG: Data collection, manuscript writing and editing. MDT: Protocol and project development, data collection, data analysis, manuscript writing and editing.

Funding This work did not receive any grant from funding agencies in the public, commercial, or not-for-profit sectors.

Availability of data and materials The authors declare that all data used in this study are fully available for reviewing and analysis.

\section{Declarations}

Conflict of interest The authors declare that they have no known competing financial or personal relationships that could be viewed as influencing the work reported in this paper.

\section{References}

1. Ateşoğlu S, Deniz M, Uslu AI (2018) Evaluation of the morphological characteristic and sex differences of sternum by multidetector computed tomography. Folia Morphol (Warsz) 77:489_ 497. https://doi.org/10.5603/FM.a2018.0002

2. Bayaroğulları H, Yengil E, Davran R, Ağlagül E, Karazincir S, Balc1 A (2014) Evaluation of the postnatal development of the sternum and sternal variations using multidetector CT. Diagn Interv Radiol 20:82-89. https://doi.org/10.5152/dir.2013.13121

3. Delgado J, Jaimes C, Gwal K, Jaramillo D, Ho-Fung V (2014) Sternal development in the pediatric population: evaluation using computed tomography. Pediatr Radiol 44:425-433. https://doi.org/ 10.1007/s00247-013-2841-8

4. Gumeler E, Akpinar E, Ariyurek OM (2019) MDCT evaluation of sternal development. Surg Radiol Anat 41:281-286. https://doi. org/10.1007/s00276-019-02189-9 
5. Moënne Bühlmann K, Araneda Castiglioni D, Ortega Flores X, Pérez Sánchez C, Escaffi Johnson J, Pérez Matta M, Godoy Lenz J (2019) Clinical and radiological study of sternal fractures in pediatrics. Estudio clínico radiológico de las fracturas esternales en edad pediátrica. Radiologia 61:234-238. https://doi.org/10. 1016/j.rx.2019.01.004

6. Yang M, Jiang H, Yu X, Chen W, Li Q, Zhang Y, Pan B (2017) Sternal development and variations and anomalies in patients with microtia:evaluation using 3-dimensional computed tomography. $\mathrm{J}$ Comput Assist Tomogr 41:784-791. https://doi.org/10.1097/RCT. 0000000000000590

7. Arnáiz-García ME, González-Santos JM, Arnáiz-García AM, López-Rodríguez J, Arnáiz J (2017) Acute type A aortic dissection after sternal bone marrow puncture. Ann Thorac Surg 104:e455. https://doi.org/10.1016/j.athoracsur.2017.07.039

8. Inoue $\mathrm{H}$, Nakasato T, Yamauchi K, Nakamura Y, Oshida S, Ehara S (2010) Risk factors concerning sternal bone marrow aspiration and patient safety in Japan. Intern Med 49:1089-1095. https://doi. org/10.2169/internalmedicine.49.3243

9. Kindermans M, Abid S, Alkhoder S, Bouadma L (2018) Pulsatile bleeding after sternal bone marrow puncture. Intensive Care Med 44:1758-1759. https://doi.org/10.1007/s00134-018-5219-4

10. Kim EY, Yang HJ, Sung YM, Hwang KH, Kim JH, Kim HS (2012) Sternal fracture in the emergency department: diagnostic value of multidetector $\mathrm{CT}$ with sagittal and coronal reconstruction images. Eur J Radiol 81:e708-e711. https://doi.org/10.1016/j. ejrad.2011.05.029
11. Weiss G, Wittig H, Scheurer E, Ruprecht R, Lenz C (2018) Identification of deceased based on sternal bone computed tomography features. Forensic Sci Int 286:233-238. https://doi.org/10.1016/j. forsciint.2018.03.018

12. Yammine K, Assi C (2017) Estimation of stature from sternal lengths. A correlation meta-analysis. Arch Med Sadowej Kryminol 67:166-177. https://doi.org/10.5114/amsik.2017.73191

13. Babinski MA, de Lemos L, Babinski MS, Gonçalves MV, De Paula RC, Fernandes RM (2015) Frequency of sternal foramen evaluated by MDCT: a minor variation of great relevance. Surg Radiol Anat 37:287-291. https://doi.org/10.1007/ s00276-014-1339-x

14. Klein C, Blondin E, Haraux E, Gouron R (2020) Sternal cleft in a newborn. Arch Dis Child Fetal Neonatal Ed 105:555. https://doi. org/10.1136/archdischild-2020-319104

15. Turkay R, Inci E, Ors S, Nalbant MO, Gurses IA (2017) Frequency of sternal variations in living individuals. Surg Radiol Anat 39:1273-1278. https://doi.org/10.1007/s00276-017-1854-7

Publisher's Note Springer Nature remains neutral with regard to jurisdictional claims in published maps and institutional affiliations. 